\title{
Article
}

\section{Driving Force Distribution and Control for Maneuverability and Stability of a 6WD Skid-Steering EUGV with Independent Drive Motors}

\author{
Hui Zhang ${ }^{1,2,3,4}$, Huawei Liang ${ }^{1,3,4, *}$, Xiang Tao ${ }^{1,3,4}$, Yi Ding ${ }^{1,3,4}$, Biao Yu 1,3,4 and Rengui Bai $^{1,2,3,4}$ \\ 1 Hefei Institutes of Physical Science, Chinese Academy of Sciences, Hefei 230031, China; \\ gloryzh@mail.ustc.edu.cn (H.Z.); xtao@hfcas.ac.cn (X.T.); yding@hfcas.ac.cn (Y.D.); byu@hfcas.ac.cn (B.Y.); \\ zaowuzhu@mail.ustc.edu.cn (R.B.) \\ 2 University of Science and Technology of China, Hefei 230026, China \\ 3 Anhui Engineering Laboratory for Intelligent Driving Technology and Application, Hefei 230031, China \\ 4 Innovation Research Institute of Robotics and Intelligent Manufacturing, Chinese Academy of Sciences, \\ Hefei 230031, China \\ * Correspondence: hwliang@iim.ac.cn; Tel./Fax: +86-551-6539-3191
}

Citation: Zhang, H.; Liang, H.; Tao, X.; Ding, Y.; Yu, B.; Bai, R. Driving Force Distribution and Control for Maneuverability and Stability of a 6WD Skid-Steering EUGV with Independent Drive Motors. Appl. Sci. 2021, 11, 961. https://doi.org/10.3390/app11030961

Academic Editor: Alessandro Gasparetto Received: 23 December 2020

Accepted: 18 January 2021

Published: 21 January 2021

Publisher's Note: MDPI stays neutral with regard to jurisdictional claims in published maps and institutional affiliations.

Copyright: (c) 2021 by the authors Licensee MDPI, Basel, Switzerland. This article is an open access article distributed under the terms and conditions of the Creative Commons Attribution (CC BY) license (https:// creativecommons.org/licenses/by/ $4.0 /)$.
Featured Application: The paper proposes a hierarchical driving force distribution and control strategy for six-wheel drive (6WD) skid-steering electric unmanned ground vehicles (EUGVs) with independent drive motors to improve the vehicle maneuverability and stability. The proposed method can be applied to control the longitudinal velocity and yaw rate for distributed, independently driven electrical skid-steering vehicles, for instance, military vehicles, agricultural vehicles, and other special vehicles.

Abstract: In this paper, a hierarchical driving force distribution and control strategy for a six-wheel drive (6WD) skid-steering electric unmanned ground vehicle (EUGV) with independent drive motors is presented to improve the vehicle maneuverability and stability. The proposed hierarchical strategy is based on a nine-degrees-of-freedom (DOFs) dynamics model of 6WD skid-steering EUGV with a vehicle system dynamics model, wheel dynamics model, and tire model. In the proposed hierarchical strategy, the upper layer controller calculates the resultant driving force and yaw moment to control the vehicle motion states to track the desired ones by using the integral sliding mode control (ISMC) and proportion-integral-differential (PID) control methods. In the lower layer controllers, the driving force distribution method is adopted to allocate torques to the six motors. An objective function is proposed and composed of the longitudinal tire workload rates and weighting factors, considering the inequality constraints and equality constraints, which is solved by using the active set method. In order to evaluate the effectiveness of the proposed method, experiments with two types of scenarios were conducted. Comparative studies were also conducted with the other two methods used in the literature. The experimental results show that better performance can be achieved with the proposed control strategy in vehicle maneuverability and stability.

Keywords: six-wheel drive (6WD); skid steering; electric unmanned ground vehicle (EUGV); driving force distribution; vehicle motion control; maneuverability and stability

\section{Introduction}

In recent years, with the development and wide application of intelligent technology, sensor technology, and control technology, the unmanned ground vehicle (UGV) is being promoted quickly and widely for military and civil usage [1-6]. UGVs are employed to replace humans in various dangerous situations for executing many tasks, for instance, battle, research, rescue, mining, firefighting, and so on. In order to reduce fuel consumption, exhaust gas emissions, and noise, many types of vehicle power source have been widely studied in industry and academic fields, such as hybrid electric vehicles (HEVs), plug-in 
hybrid electric vehicles (PHEVs), and pure electric vehicles (EVs) [2,7-10]. Currently, the electric UGV (EUGV) is attracting great research focus by reason of its wide applications and the development of electric motor and control technology. The drive forms for EUGVs are mainly divided into centralized drive systems and distributed drive systems. Compared to the centralized drive system, the distributed drive system is composed of two or more independent drive wheels. With the development of independent drive technology, EUGVs with distributed drive systems have tremendous potential to improve vehicle maneuverability and lateral stability. That is because the independent drive wheels can be directly actuated and independently controlled; the six-wheel independent drive EUGV will be focused on in this paper.

In order to realize and improve the maneuverability and lateral stability of EVs with the distributed drive system, various methods have been studied and developed for four-wheel drive (4WD) EVs driven by independent motors, and research into 6WD and $8 \mathrm{WD}$ EVs has been completed based on those achievements. An EV with independent drive wheels is an over-actuated system, and each wheel can be controlled directly and individually. Therefore, these methods mainly concentrate on vehicle motion control and driving force distribution. In vehicle motion control research, the longitudinal and lateral motion controllers have attracted great research efforts. The algorithm utilized for motion controller design in prior literature includes a proportion-integral-differential (PID) controller [11,12], H-infinite controller [13], sliding mode controller (SMC) [14-16], linear quadratic regulator (LQR) [17], and model-predicted controller (MPC) $[18,19]$. The motion controller has been applied to calculate the vehicle resultant force for tracking the longitudinal motion and vehicle's resultant yaw moment for tracking the later motion, according to the vehicle's desired input and actual output. This vehicle resultant force and yaw moment are supported by each wheel with independent drive motors. Then, the driving force distribution is the next research point. In driving force distribution research, many distribution algorithms have been proposed for realizing the EV's turning stability, reducing the tire-road slip, or improving the performance in energy consumption [20-22]. Rule-based distribution and optimization-based distribution methods are mainly applied to allocate the torque of each wheel. Due to the lack of optimality and accuracy of the rule-based distribution algorithm [23], methods based on the optimization theory are widely used to obtain optimal control inputs. The optimization theory is the law that establishes an objective function and solves its minimum by taking into account system constraints [24]. Novellis et al. [25] investigated different objective functions and constraints on the basis of the motor performance, battery capacity, and tire-road adhesion for $4 \mathrm{WD}$ EVs. Zhao et al. [26] proposed a nonlinear control distribution scheme for 4WD EVs to improve vehicle stability with the constraints of the driven motors and tire-road adhesion. Saeid Khosravani et al. [27] proposed a novel optimization allocation strategy for a vehicle's longitudinal and lateral control and verified its effectiveness by simulation and experiments. Xiong et al. $[28,29]$ investigated the directed yaw control method based on driver operation intention and designed allocation control algorithms with a dynamic efficiency matrix for the stability control of $4 \mathrm{WD}$ EVs. Not only have distribution algorithms for $4 \mathrm{WD}$ EVs been developed, but distribution algorithms for 6WD and 8WD EVs have also seen many research achievements. Kyongsu et al. [30] utilized the optimal driving force distribution for $6 \mathrm{WD} / 6 \mathrm{WS}$ EVs, in which the objective function is based on the sum of each tire's workload rate while considering tire-road adhesion and friction circle. Kim [31] investigated an objective function consisting of the sum of six tire utilization rates and minimized its value using the Lagrange multiplier method for tire force distribution. Zhang [23,32] and Kim [33] researched the driving force allocation schemes for 8WD EVs to enhance stability and maneuverability.

Nevertheless, the aforementioned literature is focused on passenger EVs, EVs with Ackerman steering gears, and few papers have concentrated on skid-steering EUGVs. Due to the difference in vehicle dynamics models between differential-steering vehicles and Ackerman-steering vehicles, there are some problems that need to be solved: (1) For 
passenger EVs and Ackerman-steering EVs, the vehicle dynamics models are established by considering the wheel steering angle. However, each wheel steering angle of the skidsteering EUGV is zero in its dynamics model. This increases the understeer behavior performance and steering difficulty factor. (2) By reason of the steering difficulty, it is a challenge to design a driving force control and distribution algorithm for tracking the desired lateral yaw rate. To this end, a novel driving force distribution and control strategy with a hierarchical controller structure is proposed in this paper and was implemented on a skid-steering EUGV. The major contributions lie in the following aspects. A nine-degreesof-freedom (DOFs) dynamics model of a 6WD skid-steering EUGV with a vehicle system dynamics model, wheel dynamics model, and tire model was established. A hierarchical controller that is composed of the upper layer controller and lower layer controller is proposed. The upper layer controller is devised to determine the resultant force and yaw moment to make sure the vehicle motion states track the desired values by using the integral sliding mode controller and PID controller. In the lower layer controller, a driving force distribution scheme is proposed based on the optimization allocation. The objective function is formulated based on the longitudinal tire workload rate and weighting factors. The weighting factors are established based on the ratio of the tire vertical force considering the vehicle motion conditions and vertical load change of each tire. Lastly, the two types of experimental scenarios with the proposed controller were tested to validate the effectiveness of the control algorithm for the skid-steering EUGV.

This paper is organized as follows. Section 2 introduces a nonlinear dynamics model of a skid-steering EUGV actuated by independent drive wheels. In Section 3, the hierarchical driving force distribution and control scheme for improving the maneuverability and stability of a 6WD skid-steering EUGV are described. Experiments with two cases of scenarios were conducted to verify the performance of the proposed controller, as described in Section 4. Finally, the conclusions are drawn in Section 5.

\section{Vehicle and Wheel Dynamics Model}

For the design of a vehicle driving force distribution control system, a 6WD skidsteering EUGV dynamics model with the wheel motor torque as the input and vehicle motion states-such as the lateral and longitudinal acceleration, longitudinal velocity, and yaw rate-as output is required. In this section, the establishment of a six-wheel vehicle dynamics model is described that includes three parts: a nonlinear vehicle system dynamics model, a wheel dynamics model, and a tire model.

\subsection{Vehicle System Dynamics Model}

In this paper, a 6WD skid-steering EUGV dynamics model was established as an object with nine degrees of freedom (DOFs). The full vehicle system dynamics model was comprised of three-DOF rotational and translational dynamic models of the body and six-wheel dynamic models. The vehicle system dynamics model considers longitudinal, lateral, and yaw dynamics and ignores roll and pitch dynamics, as shown in Figure 1. The nomenclature for the parameters, all the Equations, and all the symbols seen in Figure 1 , can be found in Nomenclature. In Figure 1, ox represents the longitudinal direction of the coordinate system and oy represents the lateral direction of the coordinate system. According to the Newtonian and Euler Theorem, the longitudinal and lateral dynamic equations are

$$
\left\{\begin{array}{l}
m\left(\dot{v}_{x}-\omega v_{y}\right)=F_{x} \\
m\left(\dot{v}_{y}+\omega v_{x}\right)=F_{y}
\end{array},\right.
$$

where

$$
\left\{\begin{array}{l}
F_{x}=F_{x 1}+F_{x 2}+F_{x 3}+F_{x 4}+F_{x 5}+F_{x 6} \\
F_{y}=F_{y 1}+F_{y 2}+F_{y 3}+F_{y 4}+F_{y 5}+F_{y 6}
\end{array},\right.
$$

and the rotational dynamic equation is

$$
I_{z} \dot{\omega}=M_{F x}+M_{F y}
$$


where

$$
\left\{\begin{array}{l}
M_{F x}=\frac{B}{2}\left(F_{x 2}+F_{x 4}+F_{x 6}-F_{x 1}-F_{x 3}-F_{x 5}\right) \\
M_{F y}=\left(l_{1}+a\right)\left(F_{y 1}+F_{y 2}\right)+a\left(F_{y 3}+F_{y 4}\right)-\left(l_{2}-a\right)\left(F_{y 5}+F_{y 6}\right)
\end{array},\right.
$$

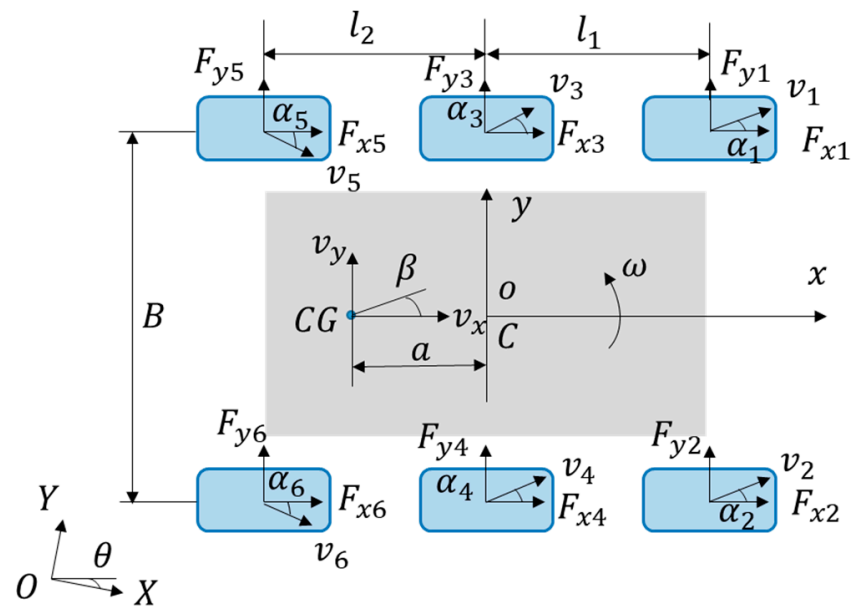

Figure 1. Schematic diagram of the vehicle dynamics model.

Thus, the wheel sideslip angles are calculated according to

$$
\left\{\begin{array}{rl}
\alpha_{1} & =\arctan \frac{v_{y}+\left(l_{1}+a\right) \omega}{v_{x}-\frac{B}{2} \omega} \\
\alpha_{2} & =\arctan \frac{v_{y}+\left(l_{1}+a\right) \omega}{v_{x}+\frac{B}{2} \omega} \\
\alpha_{3} & =\arctan \frac{v_{y}+a \omega}{v_{x}-\frac{B}{2} \omega} \\
\alpha_{4} & =\arctan \frac{v_{y}+a \omega}{v_{x}+\frac{B}{2} \omega} \\
\alpha_{5} & =\arctan \frac{v_{y}-\left(l_{2}-a\right) \omega}{v_{x}-\frac{B}{2} \omega} \\
\alpha_{6} & =\arctan \frac{v_{y}-\left(l_{2}-a\right) \omega}{v_{x}+\frac{B}{2} \omega}
\end{array},\right.
$$

The vertical forces of the six wheels are calculated according to

$$
\left\{\begin{array}{l}
F_{z 1}=\frac{\left(l_{2}{ }^{2}-a l_{1}-a l_{2}+l_{1} l_{2}\right)\left(\frac{1}{2} m g-\frac{H}{B} m a_{y}\right)-\frac{1}{2}\left(l_{1}+l_{2}\right) m a_{x} H}{2\left(l_{1}{ }^{2}+l_{1} l_{2}+l_{2}{ }^{2}\right)} \\
F_{z 2}=\frac{\left(l_{2}{ }^{2}-a l_{1}-a l_{2}+l_{1} l_{2}\right)\left(\frac{1}{2} m g+\frac{H}{B} m a_{y}\right)-\frac{1}{2}\left(l_{1}+l_{2}\right) m a_{x} H}{2\left(l_{1}{ }^{2}+l_{1} l_{2}+l_{2}{ }^{2}\right)} \\
F_{z 3}=\frac{\left(l_{1}{ }^{2}+a l_{1}-a l_{2}+l_{2}{ }^{2}\right)\left(\frac{1}{2} m g-\frac{H}{B} m a_{y}\right)+\frac{1}{2}\left(l_{1}-l_{2}\right) m a_{x} H}{2\left(l_{1}{ }^{2}+l_{1} l_{2}+l_{2}{ }^{2}\right)} \\
F_{z 4}=\frac{\left(l_{1}{ }^{2}+a l_{1}-a l_{2}+l_{2}{ }^{2}\right)\left(\frac{1}{2} m g+\frac{H}{B} m a_{y}\right)+\frac{1}{2}\left(l_{1}-l_{2}\right) m a_{x} H}{2\left(l_{1}{ }^{2}+l_{1} l_{2}+l_{2}{ }^{2}\right)} \\
F_{z 5}=\frac{\left(l_{1}{ }^{2}+a l_{2}+l_{1} l_{2}\right)\left(\frac{1}{2} m g-\frac{H}{B} m a_{y}\right)+\frac{1}{2}\left(l_{1}+2 l_{2}\right) m a_{x} H}{2\left(l_{1}{ }^{2}+l_{1} l_{2}+l_{2}{ }^{2}\right)} \\
F_{z 6}=\frac{\left(l_{1}{ }^{2}+a l_{2}+l_{1} l_{2}\right)\left(\frac{1}{2} m g+\frac{H}{B} m a_{y}\right)+\frac{1}{2}\left(l_{1}+2 l_{2}\right) m a_{x} H}{2\left(l_{1}{ }^{2}+l_{1} l_{2}+l_{2}{ }^{2}\right)}
\end{array},\right.
$$

\subsection{Wheel Dynamics Equation}

A wheel dynamics model constructs the relationship between the driving or braking torque, wheel rotational acceleration, and longitudinal forces. Here, the rolling resistance was considered. The wheel dynamics equation is shown in Figure 2. 


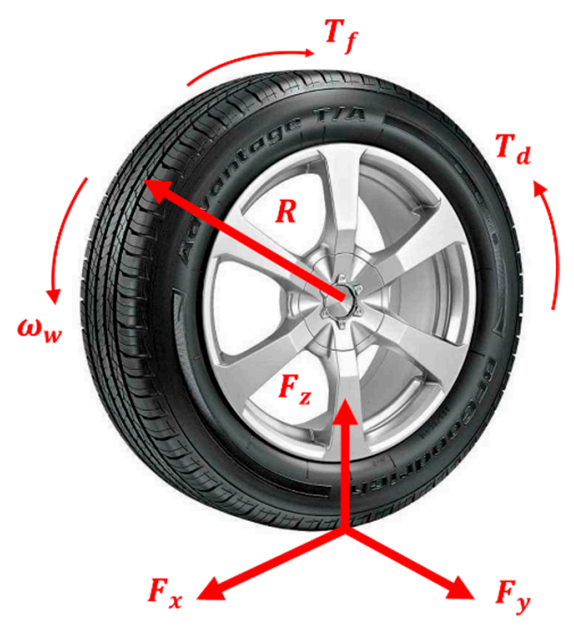

Figure 2. Schematic diagram of the wheel dynamics equation.

In Figure 2, $T_{d}$ is the motor driving or braking torque $\left(T_{d}>0\right.$ for the driving torque and $T_{d}<0$ for the braking torque), $F_{x}$ is the tire longitudinal force, $R$ is the tire effective radius, $T_{f}$ is the rolling resistance torque of the tires, and its direction is opposite to $T_{d}$.

The wheel dynamics model is expressed by Equation (7) as follows:

$$
J_{w} \dot{\omega}_{w}=T_{d}-T_{f}-F_{x} R,
$$

where $J_{w}$ is the wheel moment of inertia, and $\dot{\omega}_{w}$ is the derivative of the wheel rotation speed.

\subsection{Tire Model}

When a vehicle is driven on the road, the interaction forces between the vehicle and the road are determined by the interaction between the tires and the road. Therefore, tire forces are a key factor in the dynamic control of the vehicle, and tire force calculation models are necessary. It is well known that there are many tire models for calculating interaction forces, such as the Burckhardt tire model, Dugoff tire model, UniTire tire model, and Magic Formula tire model. Since the Magic Formula tire model has high accuracy in calculating longitudinal and lateral tire forces, especially when the tire has a large longitudinal slip rate and large lateral sideslip angle, it was chosen for calculating the tire forces in this paper.

The Magic Formula tire model is a semi-empirical tire model that is widely used in vehicle engineering. It uses a uniform formula to calculate the longitudinal and lateral forces of tires. The formula of the model is shown in Equation (8) [34].

$$
\left\{\begin{array}{l}
x=X+S_{x} \\
y(x)=D \sin \{C \arctan [B x-E(B x-\arctan (B x))]\} \\
Y=y+S_{y}
\end{array}\right.
$$

where $X$ represents the longitudinal slip rate or lateral sideslip angle of the tire in a pure situation, and $Y$ represents the longitudinal force or lateral force of the tire in a pure situation. In Equation (8), when $X$ represents the longitudinal slip rate, $Y$ represents the longitudinal force, and when $X$ represents the lateral sideslip angle, $Y$ represents the lateral force. $S_{x}$ and $S_{y}$ are correcting parameters. $B, C, D$, and $E$ are the performance parameters determined from the testing data. Figure 3 shows the longitudinal force and lateral force in pure slip circumstances, varying with the different vertical loads of the tire. $\left(F_{z}=1000,2000,3000,4000\right.$, and $\left.5000 \mathrm{~N}\right)$. Figure $3 a$ presents the longitudinal force of the tire in pure slip circumstances, according to varying values of the tire vertical load from 1000 to $5000 \mathrm{~N}$ and varying values of the tire longitudinal slip rate from -0.3 to 0.3 . Figure $3 b$ presents the lateral force of the tire in pure slip circumstances, according to varying values of the tire vertical load from 1000 to $5000 \mathrm{~N}$ and varying values of the tire lateral sideslip angle from $-30^{\circ}$ to $30^{\circ}$. 


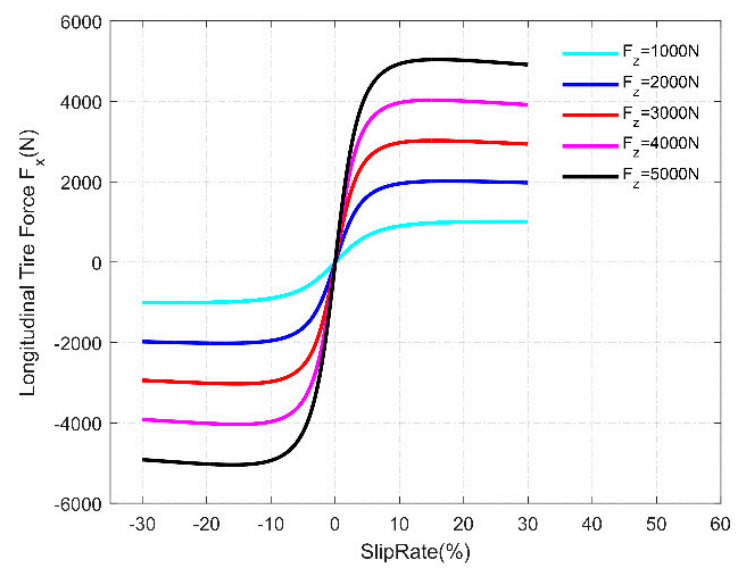

(a)

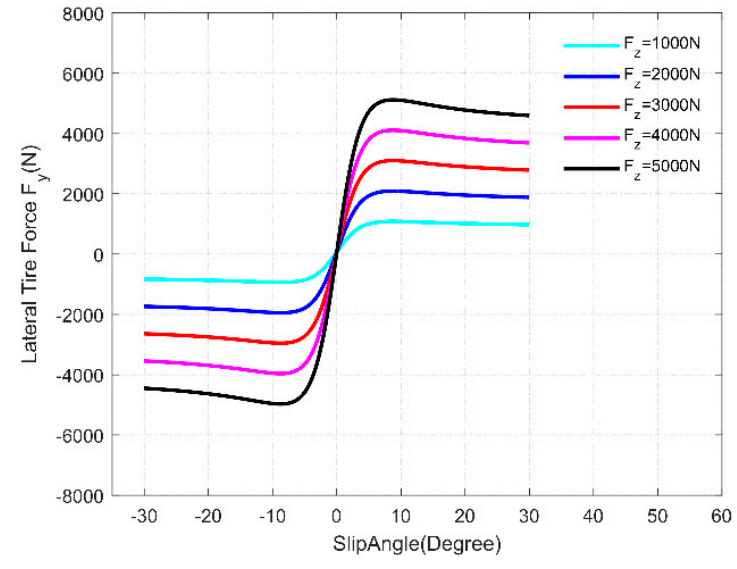

(b)

Figure 3. Longitudinal force and lateral force in pure slip circumstances. (a) Longitudinal force in pure slip circumstances, with slip rates from -0.3 to 0.3 ; (b) Lateral force in pure slip circumstances, with sideslip angles from $-30^{\circ}$ to $30^{\circ}$.

Furthermore, the tire works with longitudinal slip and lateral slip in many cases, which are called combined slip situations. In the case of combined slip situations, the calculation of the longitudinal and lateral forces of the tire can be performed as follows [34]:

$$
\left\{\begin{array}{l}
F_{x}^{*}=F_{x 0}-\varepsilon\left(F_{x 0}-F_{y 0}\right)\left(\frac{\sigma_{y}^{*}}{\sigma_{\text {total }}^{*}}\right)^{2}, \\
F_{y}^{*}=F_{y 0}-\varepsilon\left(F_{y 0}-F_{x 0}\right)\left(\frac{\sigma_{*}^{*}}{\sigma_{\text {total }}^{*}}\right)^{2},
\end{array}\right.
$$

where the total normalized slip $\sigma_{\text {total }}^{*}=\sqrt{\sigma_{x}^{* 2}+\sigma_{y}^{* 2}}$ and $\sigma_{x}^{*}=\frac{\sigma_{x}}{\sigma_{x m a x}}, \sigma_{y}^{*}=\frac{\sigma_{y}}{\sigma_{y \max }} . \varepsilon=$ $\min \left(\sigma_{\text {total }}^{*}, 1\right)$. The theoretical slips are normalized by the peak slip values, $\sigma_{x \max }$ and $\sigma_{y \max }$. $\sigma_{x}$ and $\sigma_{y}$ are calculated according to

$$
\left\{\begin{array}{l}
\sigma_{x}=-\frac{k}{1+k} \\
\sigma_{y}=\frac{\tan \alpha}{1+k}
\end{array},\right.
$$

The equivalent longitudinal and lateral slips are calculated from the normalized total theoretical slip according to

$$
\left\{\begin{array}{l}
k^{\prime}=-\frac{\sigma_{\text {total }}^{*} \sigma_{\text {xmax }} \operatorname{sign}\left(\sigma_{x}\right)}{1+\sigma_{\text {total }}^{\text {tot }} \sigma_{\text {xmax }} \operatorname{sign}\left(\sigma_{x}\right)} \\
\alpha^{\prime}=\tan ^{-1}\left[\sigma_{\text {total }}^{*} \sigma_{\text {ymax }} \operatorname{sign}\left(\sigma_{y}\right)\right]
\end{array},\right.
$$

Using the equivalent longitudinal and lateral slips and ignoring the effect of the friction ratio, the longitudinal force and lateral force in Equation (12) are obtained according to

$$
\left\{\begin{array}{l}
F_{x 0}=F X\left(F z, k^{\prime}\right) \\
F_{y 0}=F Y\left(F z, \alpha^{\prime}\right)
\end{array}\right.
$$

where $F X$ and $F Y$ are the pure slip situation tire force functions according to Equation (8).

The longitudinal force and lateral force in the combined slip circumstances are shown in Figure 4; the tire vertical load is set to 2000 N. Figure 4a presents the longitudinal force of the tire when the tire vertical load is $2000 \mathrm{~N}$, according to varying values of the tire longitudinal slip rate from 0 to 0.6 and varying values of the tire lateral sideslip angle from $0^{\circ}$ to $30^{\circ}$. Figure $4 \mathrm{~b}$ presents the lateral force of tire when the tire vertical load is $2000 \mathrm{~N}$, according to varying values of the tire longitudinal slip rate from 0 to 0.6 and varying values of the tire lateral sideslip angle from $0^{\circ}$ to $30^{\circ}$. 


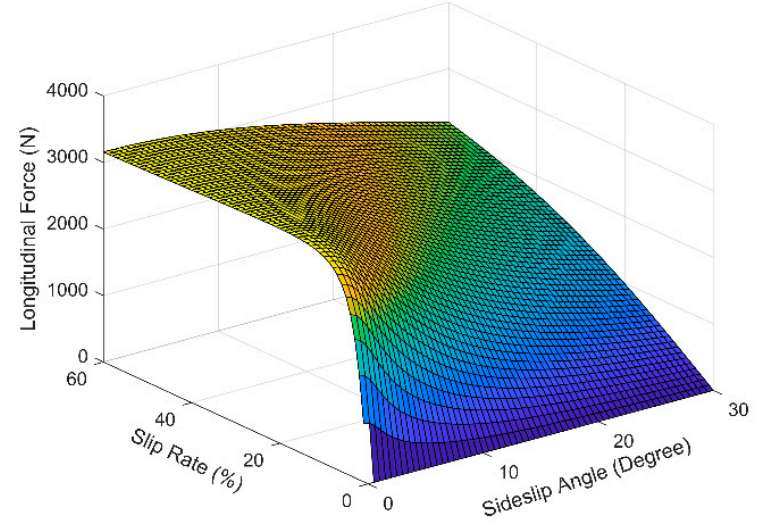

(a)

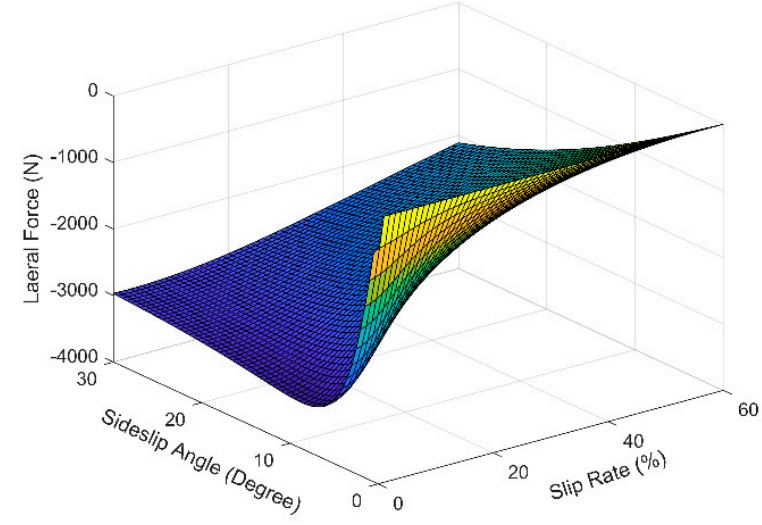

(b)

Figure 4. Longitudinal force and lateral force in combined slip circumstances; the slip rate is from 0 to 0.6 , and the sideslip angle is from $0^{\circ}$ to $30^{\circ}$. (a) Longitudinal force; (b) Lateral force.

\section{Driving Force Distribution and Control Strategy}

\subsection{Hierarchical Control Scheme}

In this paper, vehicle motion control was implemented through a driving force distribution and control algorithm. There are two layers of processing in the hierarchical scheme: the upper layer controller and the lower layer controller, as shown in Figure 5. In the parsing layer, the desired state, including the desired longitudinal speed and the desired yaw rate, is obtained by parsing the inputs from the remote control. In the tire force estimation, the tire lateral forces are estimated by referring to [35]. In order to track the desired input state of the vehicle, an upper layer controller is proposed for calculating the desired resultant force and the desired resultant yaw moment. Since the desired resultant force and the desired resultant yaw moment are generated by the interaction between the six tires and the road, a lower layer controller was designed to distribute the driving force or torque of the six motors.

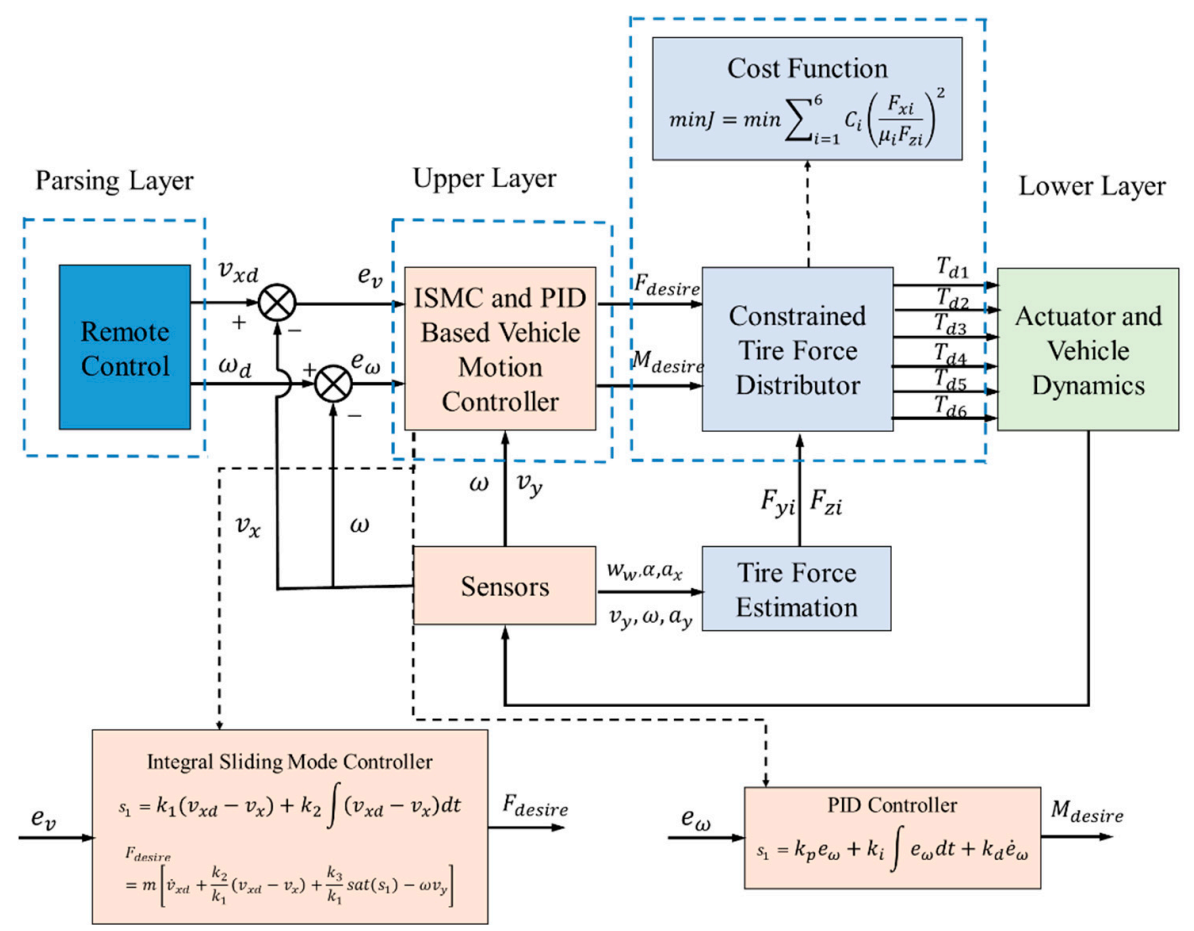

Figure 5. Schematic diagram of the controller. 


\subsection{Upper Layer Controller for Vehicle Motion Control}

In order to eliminate the error between the desired state input of the vehicle and the feedback measurement state, the upper layer controller was designed to calculate the desired resultant force and the desired resultant yaw moment for tracking the desired inputs. According to Equations (1) and (3), the desired longitudinal velocity and the desired yaw rate can be independently controlled by the desired resultant force and the desired resultant yaw moment, respectively. Due to the external perturbations and nonlinear dynamics in the vehicle motion, the integral sliding mode control (ISMC) algorithm and PID can handle these perturbations and nonlinear dynamics with good robustness. Therefore, ISMC and PID were applied to solve the problem in the upper layer controller as described in the following sections of this paper.

\subsubsection{Longitudinal Velocity Control}

Based on Equation (1), the longitudinal velocity is determined by the longitudinal tire forces. Thus, the longitudinal velocity controller was designed to calculate the desired resultant force to track the desired longitudinal velocity. To decrease the tracking error, a sliding surface was defined by

$$
s=k_{1}\left(v_{x d}-v_{x}\right)+k_{2} \int\left(v_{x d}-v_{x}\right) d t,
$$

Because of the chattering characteristics of the ISMC algorithm, it causes the tracking error to oscillate within the sliding surface. In order to reduce the chattering, an exponential reaching law with a saturation function is given:

$$
\dot{s}=-k_{3} \operatorname{sat}(s)
$$

where

$$
\operatorname{sat}(s)=\left\{\begin{array}{ll}
\operatorname{sgn}(s) & ,|s| \geq \phi \\
\frac{s}{\phi} & ,|s|<\phi
\end{array},\right.
$$

where $k_{1}>0$ and $\phi$ is the sliding boundary layer thickness; $0<\phi<1$.

Combined with Equations (13)-(15), the following can be used to deduce the desired longitudinal force for tracking the desired longitudinal velocity:

$$
\begin{gathered}
\dot{v}_{x}=\dot{v}_{x d}+\frac{k_{2}}{k_{1}}\left(v_{x d}-v_{x}\right)+\frac{k_{2}}{k_{1}} s a t(s) \\
\left.F_{\text {desire }}=m\left[\dot{v}_{x d}+\frac{k_{2}}{k_{1}}\left(v_{x d}-v_{x}\right)+\frac{k_{2}}{k_{1}} s a t(s)-\omega v_{y}\right]\right),
\end{gathered}
$$

\subsubsection{Yaw Rate Control}

The yaw rate controller was designed to calculate the desired resultant yaw moment to force the vehicle to follow the desired yaw rate using PID control as follows.

$$
M_{\text {desire }}=I_{z} \dot{\omega}_{d},
$$

where

$$
\dot{\omega}_{d}=\left[K_{p}\left(\omega_{d}-\omega\right)+K_{i} \int\left(\omega_{d}-\omega\right) d t+K_{d} \frac{d}{d t}\left(\omega_{d}-\omega\right)\right] .
$$

\subsection{Lower Layer Controller for Driving Force Distribution}

In the previous section, the ISMC and PID controller were used to calculate the desired resultant force and the desired resultant yaw moment. The vehicle has six motors driving each of the six wheels; that is to say that it is an over-actuation system. Thus, it is necessary to propose a practical driving force distribution algorithm. Since the motors can only 
provide longitudinal force to the wheels, the longitudinal force required for the wheels needs to be derived from Equation (18) as follows.

$$
\left\{\begin{array}{l}
F_{x d e s i r e}=F_{x 1 d}+F_{x 2 d}+F_{x 3 d}+F_{x 4 d}+F_{x 5 d}+F_{x 6 d} \\
M_{\text {Fxdesire }}=\frac{B}{2}\left(F_{x 2 d}+F_{x 4 d}+F_{x 6 d}-F_{x 1 d}-F_{x 3 d}-F_{x 5 d}\right)
\end{array},\right.
$$

where $F_{x i d}(i=1,2, \cdots, 6)$ denote the desired longitudinal forces provided by the motors. According to the 6WD skid-steering EUGV dynamics model and upper layer controller, $F_{x d e s i r e}=F_{\text {desire }}$ and $M_{F x \text { desire }}=M_{\text {desire }}-\sum M_{F y} \cdot \sum M_{F y}$ can be calculated with Equation (4) based on the lateral force estimation of the tire. Therefore, the desired driving forces $F_{x i d}$ of the motors are obtained, and the desired driving torques $T_{d i}$ of the motors are calculated by

$$
T_{d i}=R F_{x i d}
$$

Equation (18) describes the mathematical relationship between the driving forces of the six motors, but working out how to determine the output force of each motor is a problem. The driving force distribution algorithm is the solution to this problem. Now, the longitudinal tire workload rate $\eta$ is defined as

$$
\eta=\frac{F_{x}}{\mu F_{z}}
$$

where the tire longitudinal workload rate $\eta$ influences the vehicle driving capability and dynamic stability. To achieve optimal maneuverability and stability control, an objective function is defined according to

$$
\min J=\min \sum_{i=1}^{6} C_{i} \eta_{i}{ }^{2}=\min \sum_{i=1}^{6} C_{i}\left(\frac{F_{x i}}{\mu_{i} F_{z i}}\right)^{2},
$$

where $C_{i}(i=1,2, \cdots, 6)$ are weighting factors. In this paper, we propose that the weighting factors in the objective function can dynamically change according to the vehicle motion conditions and the vertical load of each tire. Since the vertical loads of the same side tires of the 6WD skid-steering EUGV are different, in order to dynamically adjust the longitudinal tire workload rates of the same-side wheels, the weighting factors are determined according to

$$
\left\{\begin{array}{l}
C_{1}=C_{2}=1 \\
C_{3}=\frac{F_{z 3}}{F_{z 1}} \\
C_{4}=\frac{F_{z 4}}{F_{z 2}} \\
C_{5}=\frac{F_{z 5}}{F_{z 1}} \\
C_{6}=\frac{F_{z 6}}{F_{z 2}}
\end{array},\right.
$$

There are several types of inequality constraints in the solving process for the objective function, including actuator constraints, road adhesion constraints, and tire friction circle constraints.

$$
\left\{\begin{array}{l}
\frac{T_{i m i n}}{R} \leq F_{x i} \leq \frac{T_{i m a x}}{R} \\
-\mu_{i} F_{z i} \leq F_{x i} \leq \mu_{i} F_{z i} \\
-\sqrt{\left(\mu_{i} F_{z i}\right)^{2}-\left(F_{y i}\right)^{2}} \leq F_{x i} \leq \sqrt{\left(\mu_{i} F_{z i}\right)^{2}-\left(F_{y i}\right)^{2}}
\end{array},\right.
$$

Thus, a comprehensive cost function for the driving force distribution with equality and inequality constraints is established according to

$$
\left\{\begin{array}{l}
\min J=\frac{1}{2} x^{T} W x \\
\text { s.t. }\left\{\begin{array}{l}
\boldsymbol{b}-A \boldsymbol{x}=\mathbf{0} \\
\max \left(\frac{T_{i \min }}{R},-\sqrt{\left(\mu_{i} F_{z i}\right)^{2}-\left(F_{y i}\right)^{2}}\right) \leq F_{x i d} \leq \\
\min \left(\frac{T_{\text {imax }}}{R}, \sqrt{\left(\mu_{i} F_{z i}\right)^{2}-\left(F_{y i}\right)^{2}}\right)
\end{array},\right.
\end{array}\right.
$$




$$
\begin{aligned}
& x=\left[F_{x 1 d}, F_{x 2} d, F_{x 3 d}, F_{x 4 d}, F_{x 5 d}, F_{x 6 d}\right]^{T}, \\
& A=\left[\begin{array}{cccccc}
1 & 1 & 1 & 1 & 1 & 1 \\
-\frac{B}{2} & \frac{B}{2} & -\frac{B}{2} & \frac{B}{2} & -\frac{B}{2} & \frac{B}{2}
\end{array}\right], \\
& W=\left[\begin{array}{cccccc}
C_{1} /\left(\mu_{1} F_{z 1}\right)^{2} & 0 & 0 & 0 & 0 & 0 \\
0 & C_{2} /\left(\mu_{2} F_{z 2}\right)^{2} & 0 & 0 & 0 & 0 \\
0 & 0 & C_{3} /\left(\mu_{3} F_{z 3}\right)^{2} & 0 & 0 & 0 \\
0 & 0 & 0 & C_{4} /\left(\mu_{4} F_{z 4}\right)^{2} & 0 & 0 \\
0 & 0 & 0 & 0 & C_{5} /\left(\mu_{5} F_{z 5}\right)^{2} & 0 \\
0 & 0 & 0 & 0 & 0 & C_{6} /\left(\mu_{6} F_{z 6}\right)^{2}
\end{array}\right] \\
& \boldsymbol{b}=\left[F_{x \text { desire }}, M_{\text {Fxdesire }}\right]^{T},
\end{aligned}
$$

The optimal solution $F_{x i}$ from solving the comprehensive cost function (24) is transformed into a problem of quadratic programming $(\mathrm{QP})$ with equality constraints and inequality constraints, which can be solved by using the active set method.

\section{Experimental Results}

\subsection{Experimental Platform and Projects}

In order to verify the performance of the proposed distribution control method, experiments were implemented as described in this section. The experimental platform used for the validation is shown in Figure 6.

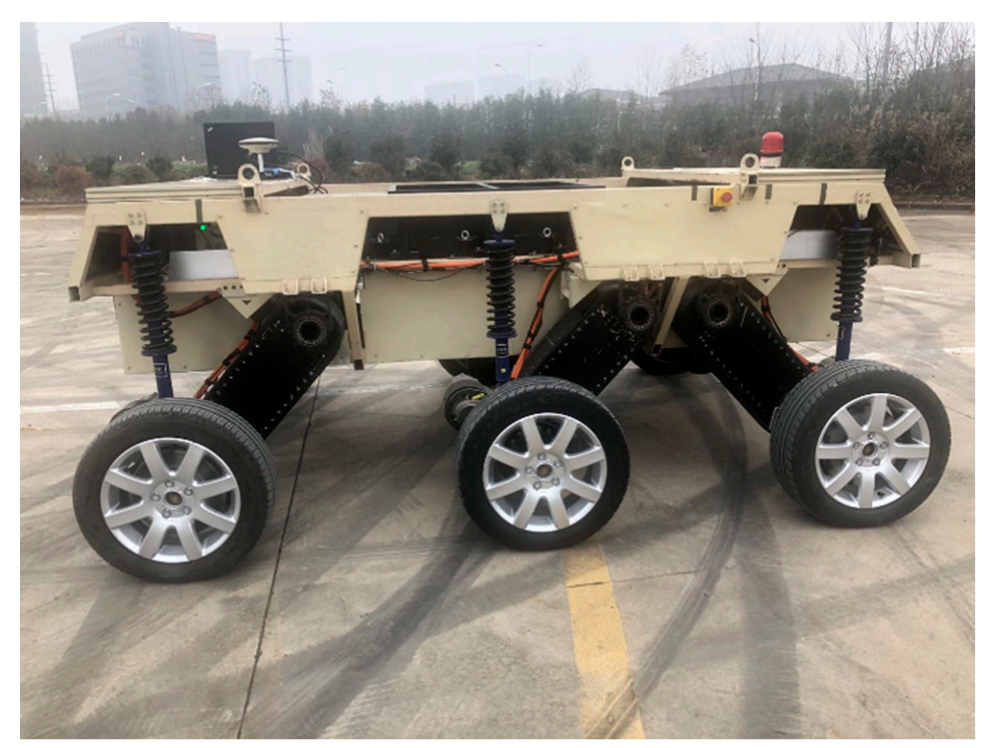

Figure 6. The experimental platform.

The studied vehicle can be regarded as a combination of six wheel corners, a body, and other components. Each wheel corner consists of an independent electrical drive motor system and a suspension system. Each wheel cannot steer, and the platform steers by skidding. Therefore, the experimental platform is a 6WD skid-steering EUGV. The tire model configured in the platform is 205/55 R16. The other components include a GPS/IMU, computer, and wireless receiver module. The model of the GPS/IMU is XW-GI7660. The platform parameters are listed in Table 1. 
Table 1. Parameters of the experimental platform.

\begin{tabular}{ccc}
\hline Symbol & Parameters & Value and Units \\
\hline$m$ & Vehicle total mass & $2020 \mathrm{~kg}$ \\
$I_{z}$ & Yaw moment of inertia of the vehicle & $1897 \mathrm{~N} \cdot \mathrm{m}$ \\
$a$ & Distance from center of gravity to the middle axle & $0.2 \mathrm{~m}$ \\
$B$ & Vehicle width & $2.2 \mathrm{~m}$ \\
$H$ & Height of center of gravity & $0.68 \mathrm{~m}$ \\
$l_{1}$ & Distance from the front axle to the middle axle & $1.2 \mathrm{~m}$ \\
$l_{2}$ & Distance from the middle axle to the rear axle & $1.206 \mathrm{~m}$ \\
$J_{w}$ & Rotation moment of the wheel & $0.85 \mathrm{~kg} \cdot \mathrm{m}^{2}$ \\
$R$ & Wheel effective radius & $0.308 \mathrm{~m}$ \\
\hline
\end{tabular}

Figure 7 shows the details of the hardware of the platform. The desired control signals are sent by the operator via the operating remote control and received by the computer via the wireless receiver module. The motion status of the vehicle, including the longitudinal and lateral velocity, heading, yaw rate, and accelerations, was measured with the GPS/IMU system in the vehicle. The proposed distribution and control algorithm was employed in the computer, while the computer sent the control signals to the motor controller and received the feedback signals from the independent drive motors through the CAN bus.

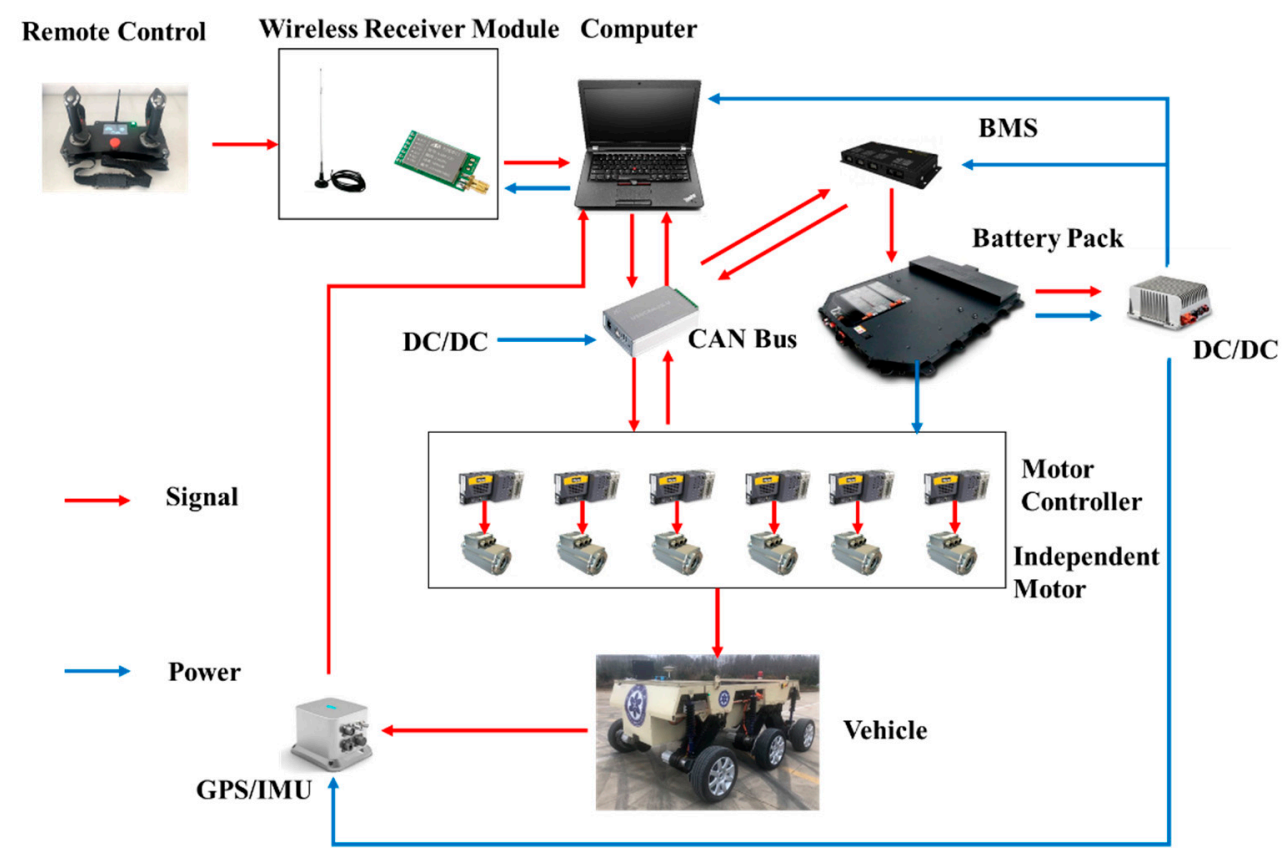

Figure 7. The hardware of the six-wheel-drive (6WD) skid-steering electric unmanned ground vehicle (EUGV) platform.

In order to demonstrate the excellent performance of the algorithm proposed in this paper, three control methods for experiments were used:

Method 1: Platform under the rule-based driving force even distribution method in [23], which is marked by Ref1.

Method 2: Platform under the optimal driving force vectoring distribution method in [15], which is marked by Ref2.

Method 3: Platform under the proposed distribution control.

The 6WD skid-steering EUGV platform requires straight-line and steering tracking capabilities. Thus, two types of testing scenarios were considered:

Scenario 1: Platform motion in straight conditions.

Scenario 2: Platform motion in curved conditions.

The figures were drawn by using MATLAB R2018b. 


\subsection{Experimental Results Discussion}

\subsubsection{Experiments in Straight Conditions}

The desired longitudinal velocity of the vehicle was set to vary between 0 and $5 \mathrm{~km} / \mathrm{h}$. Figure 8 shows the desired speed at different times. At the beginning of the time, the desired speed was set to $1.8 \mathrm{~km} / \mathrm{h}$, and then, at $2 \mathrm{~s}$, the desired speed was set to $5 \mathrm{~km} / \mathrm{h}$. Figure 8 compares the response of the actual speed resulting from the three control methods. From 13 to $22 \mathrm{~s}$, the desired longitudinal velocity was set to $3 \mathrm{~km} / \mathrm{h}$. After that, from 22 to $24 \mathrm{~s}$, the desired speed was set to 0 ; from 24 to $34 \mathrm{~s}$, the desired speed was set to $-5 \mathrm{~km} / \mathrm{h}$; and from 34 to $42 \mathrm{~s}$, the desired speed was set to $-3 \mathrm{~km} / \mathrm{h}$, and then, it was set to 0 until the end. Here, a negative desired speed means an opposite motion direction relative to the starting desired motion direction. The locally magnified graph in Figure 8 shows the response of the actual velocity when the desired velocity was increased at $13 \mathrm{~s}$. As mentioned above, the longitudinal velocity tracking accuracy of the three control methods is approximate in straight conditions. Figure 9 shows the yaw rate tracking performance of the three control methods, which is similar to in the above case. Figure 9a presents the yaw rate tracking performance. The tracking errors of the three controllers are very small and nearly the same. Figure $9 \mathrm{~b}-\mathrm{d}$ present the torque on each wheel of the three controllers. The torques on each wheel with Ref2 and the proposed controller are nearly same, and are a little larger than those with Ref1.

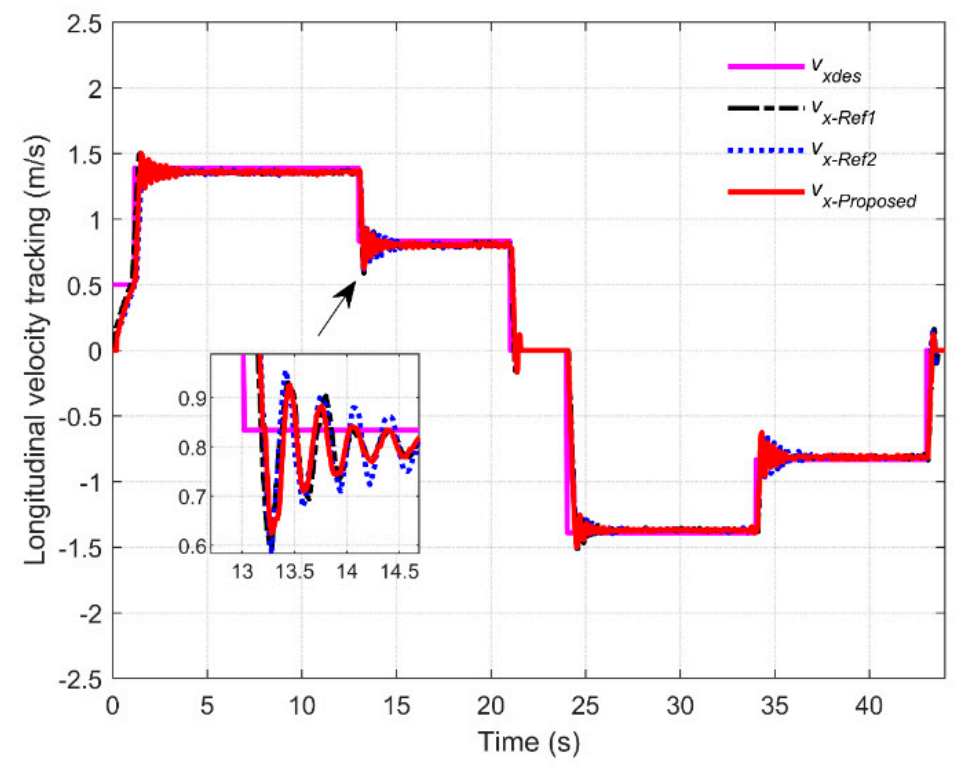

Figure 8. Longitudinal velocity tracking.

Figure 10a,b compare the responses to heading and heading error. However, while the yaw rate tracking accuracy is approximately the same for the three control methods in Figure 9, the heading and heading errors are different. Compared to at the starting point, from 0 to $25 \mathrm{~s}$, the heading errors with the Ref1 and Ref2 controllers were almost same, and the maximums were about $-0.94^{\circ}$, but the maximum of the heading error with the proposed controller was about $-0.8^{\circ}$, which was the smallest among the three controllers. After $25 \mathrm{~s}$, the heading errors with the Ref1 and the proposed controllers were almost same, and Ref2 had the largest among the three controllers. In other words, the proposed controller reduces the heading error in straight conditions. As a result, the proposed control method has better tracking performance when tracking straight conditions. 


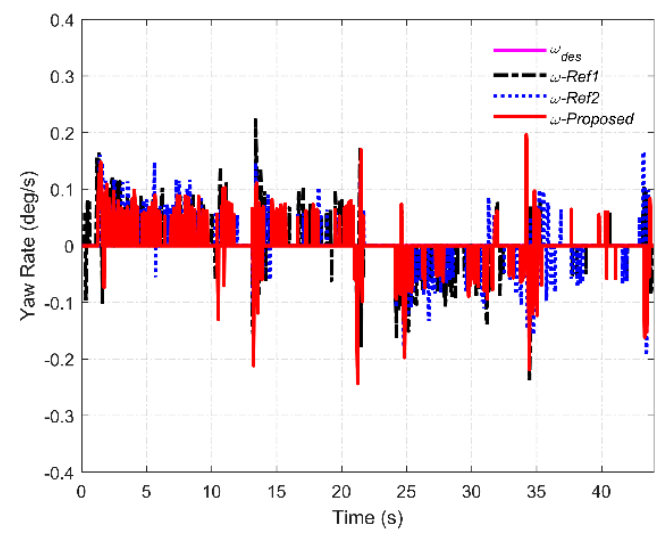

(a)

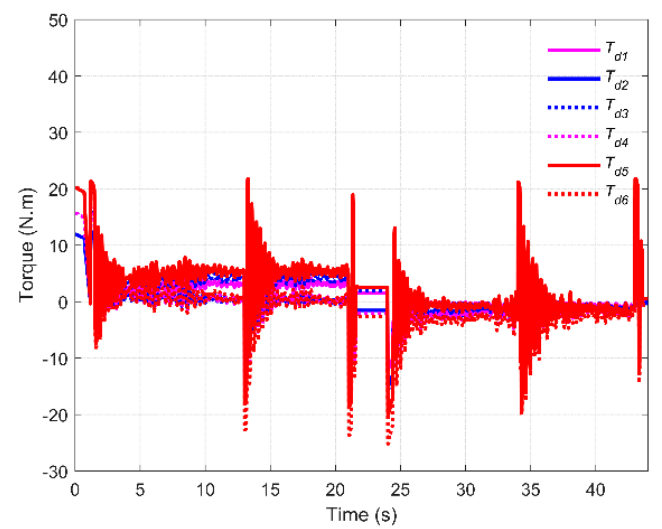

(c)

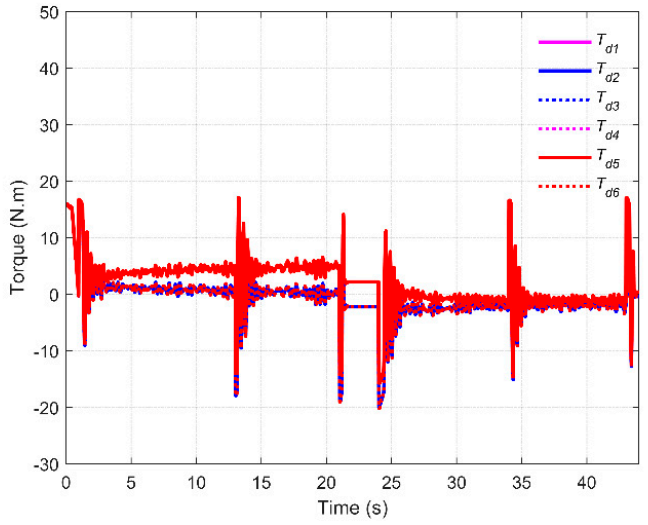

(b)

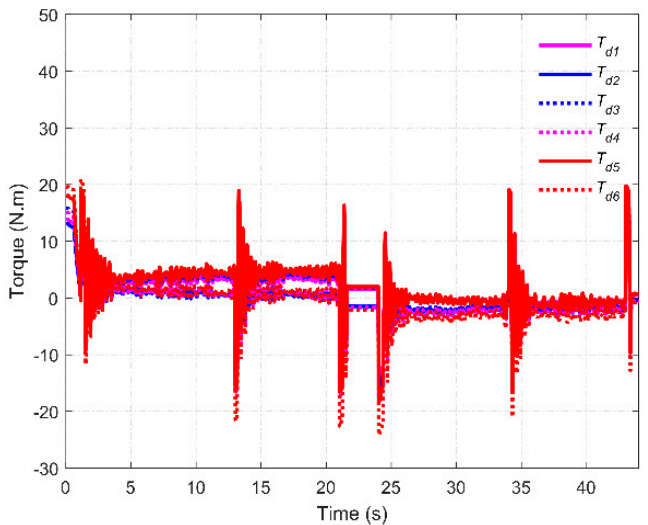

(d)

Figure 9. Comparison of yaw rate and the desired torque on each wheel with three controllers: (a) Comparison of yaw rate; (b) Torque on each wheel with Ref1 controller; (c) Torque on each wheel with Ref2 controller; (d) Torque on each wheel with the proposed controller.

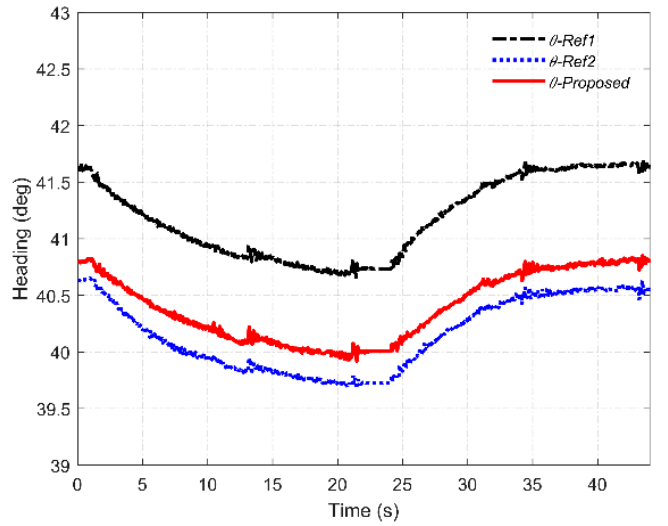

(a)

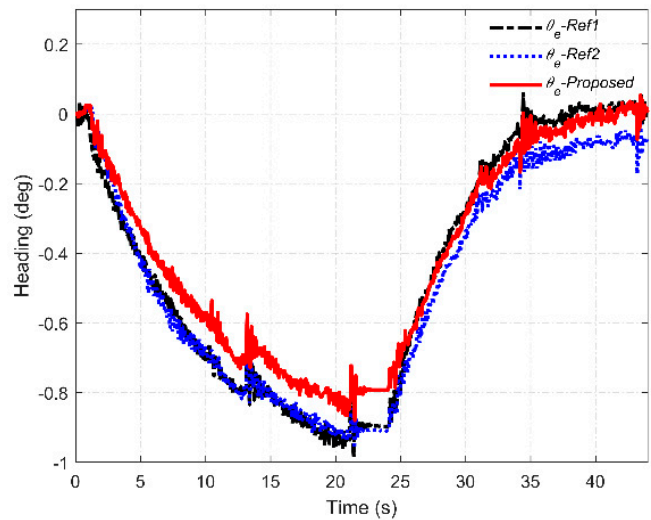

(b)

Figure 10. Comparison of heading and heading error with three controllers: (a) Comparison of heading; (b) Comparison of heading error.

Figure 11 shows the response of the sideslip angle of the vehicle. When the platform was moving in straight conditions, the value of the sideslip angle was small with the three controllers. According to Figure 8, when the desired speed underwent a step-jump change, the motor torque of each wheel, heading, and sideslip angle of the platform underwent a jump change, as shown in Figures 9, 10a and 11. To depict the performance more directly, the phase planes of the sideslip angle vs. yaw rate are shown in Figure 12. It can be 
seen that the movement of the boundary of the vehicle motion states with the proposed controller is smaller than that with the other two controllers. This means that the proposed controller has better stability performance.

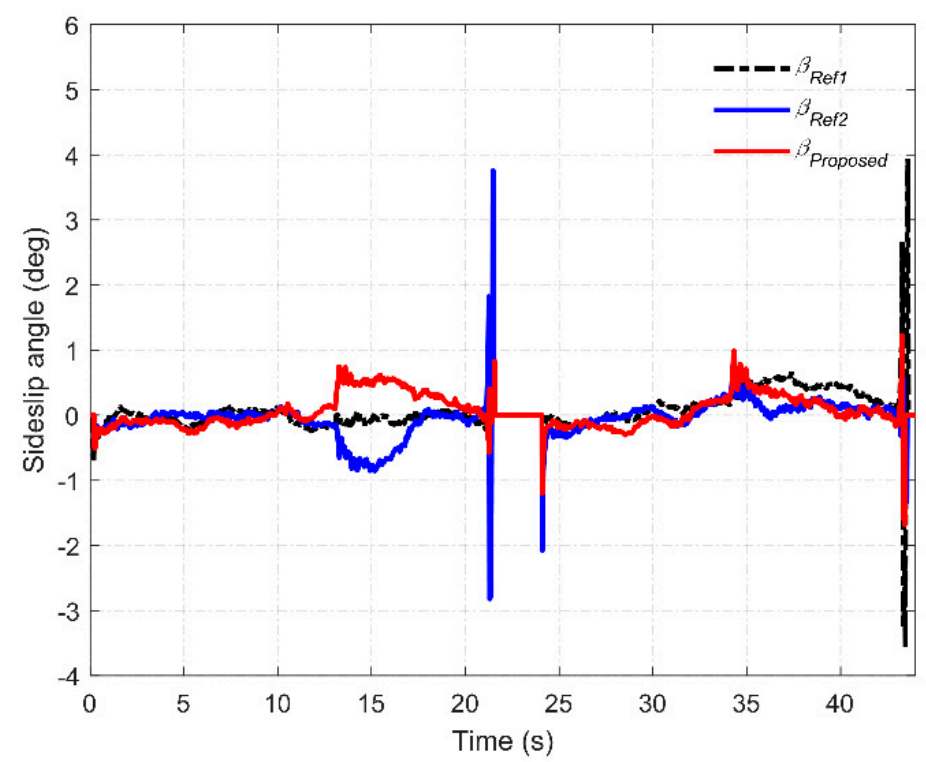

Figure 11. Comparison of sideslip angles.

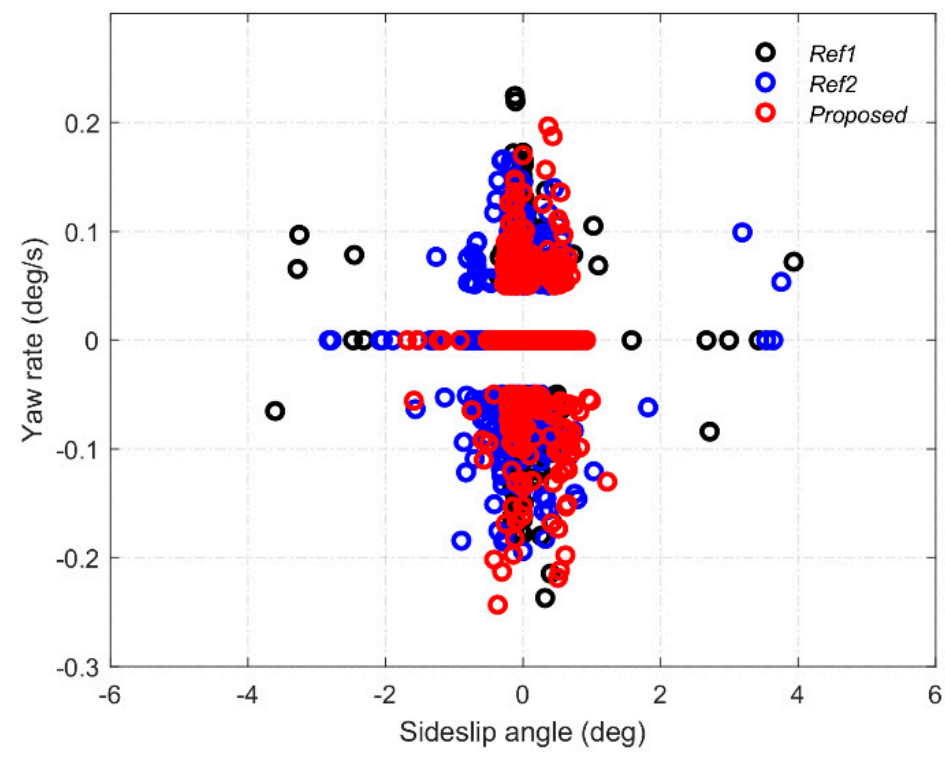

Figure 12. Comparison of phase planes.

\subsubsection{Experiments in Curved Condition}

In the curved condition experiments, the desired longitudinal velocity of the platform was set to $1.8 \mathrm{~km} / \mathrm{h}$ for $0-1.5 \mathrm{~s}, 5 \mathrm{~km} / \mathrm{h}$ for $1.5-13 \mathrm{~s}$, and 0 for 13-13.5 s, as shown in Figure 13. The desired yaw rate was set to 2.87 degrees/s from 3 to $11 \mathrm{~s}$ and 0 in other periods. The longitudinal and lateral tracking in the curve condition more rigorously verified the performance of the driving force distribution control algorithm compared to in the straight conditions. Therefore, the purpose of these experiments was to verify the maneuverability and stability performance of the proposed driving force distribution algorithm. 


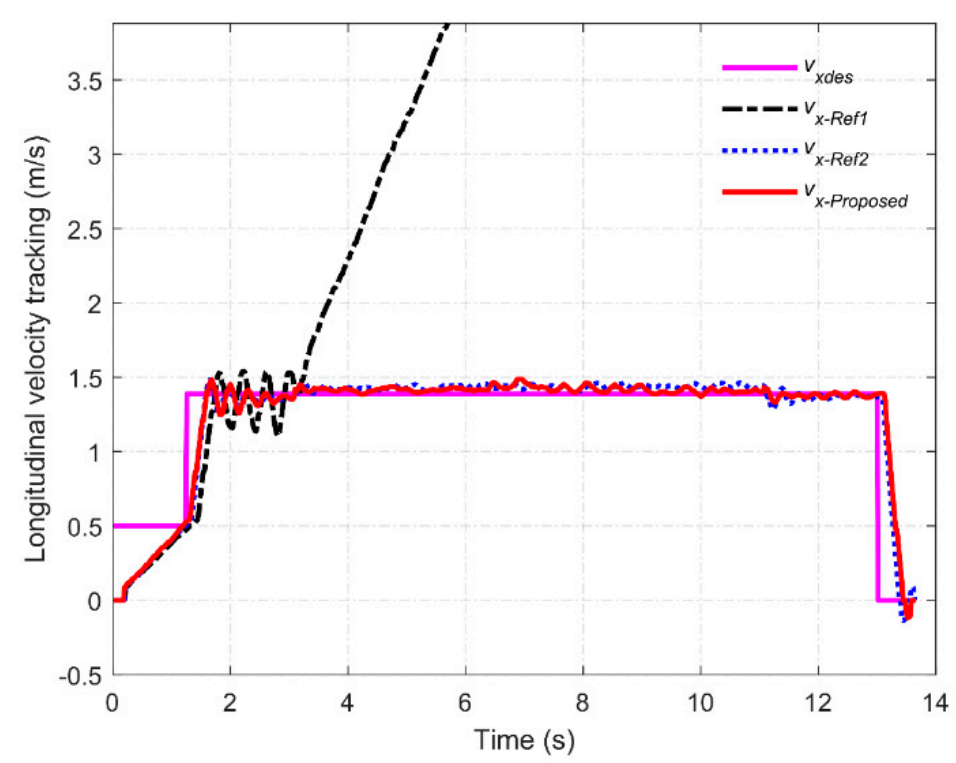

Figure 13. Longitudinal velocity tracking.

Figure 13 compared the longitudinal velocity tracking. The longitudinal velocity of the UGV platform with the Ref1 controller diverged when the desired yaw rate was not zero. At $3 \mathrm{~s}$, the desired yaw rate was set to $2.87 \mathrm{deg} / \mathrm{s}$. Then, the Ref1 controller distributed the torque on each wheel to control the platform to track the desired longitudinal velocity and yaw rate.

Since the torque on the same side of the vehicle was equal with the Ref1 controller, the vehicle's longitudinal velocity could not converge to the desired value, and the experiment was stopped at $5.8 \mathrm{~s}$. Figure $14 \mathrm{a}, \mathrm{b}$ present the longitudinal velocity tracking error and its percentage in stable tracking from 3 to $12 \mathrm{~s}$ with Ref2 and the proposed controller. There was little difference in terms of the longitudinal speed tracking accuracy between the two controllers. Figure 15 compared the yaw rate tracking. However, according to Figures 15 and 16, the yaw rate tracking error with the proposed controller was smaller than that with the Ref 2 controller in stable tracking from 5 to $11 \mathrm{~s}$. In order to observe the tracking error and accuracy more directly and clearly, the mean absolute error (MAE), root mean square error (RMSE), and standard deviation (SD) values of the errors with two controllers were calculated and are listed in Table 2 From Table 2, it can be observed that the MAEs of the longitudinal velocity and yaw rate tracking with the proposed controller were smaller than those with the Ref2 controller. According to the MAEs, compared to Ref2, the longitudinal velocity tracking error and yaw rate tracking error decreased by $33.9 \%$ and $54.5 \%$ with the proposed controller in the tracking stabilization stage, respectively. The RMSE of the yaw rate tracking with the proposed controller was smaller than that with the Ref2 controller, and the other two metrics including the RMSE of the longitudinal velocity tracking and SDs of the longitudinal and yaw rate tracking with the proposed controller were all smaller than those with the Ref2 controller. This indicates that the proposed controller has better performance in terms of longitudinal and lateral tracking accuracy. 


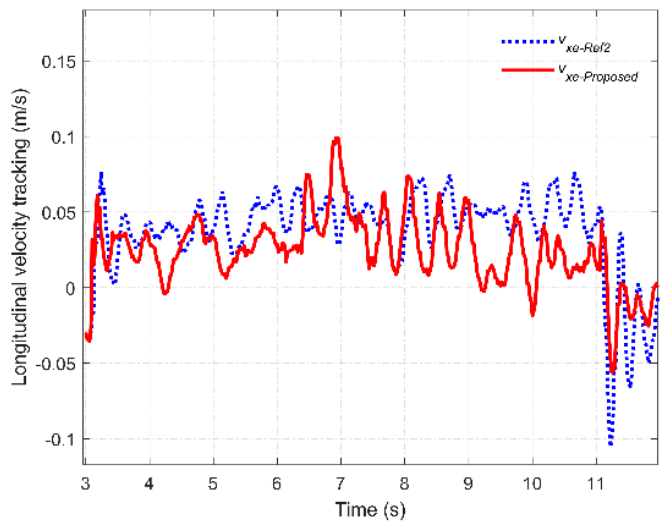

(a)

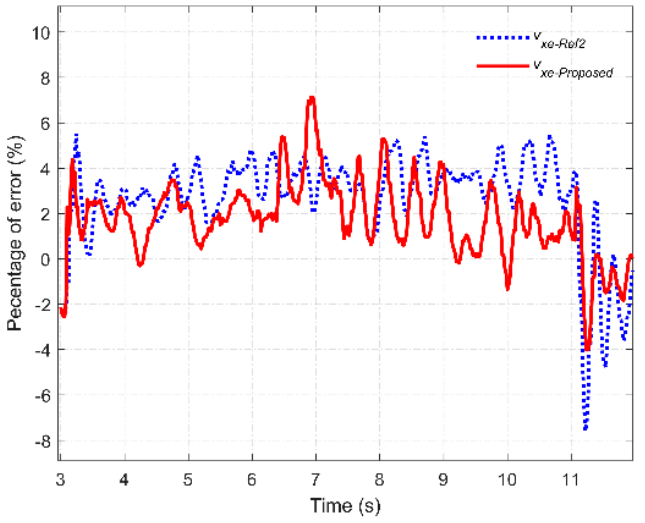

(b)

Figure 14. Comparison of longitudinal velocity tracking with two controllers: (a) Comparison of longitudinal velocity tracking error; (b) Comparison of percentage of longitudinal velocity tracking error.

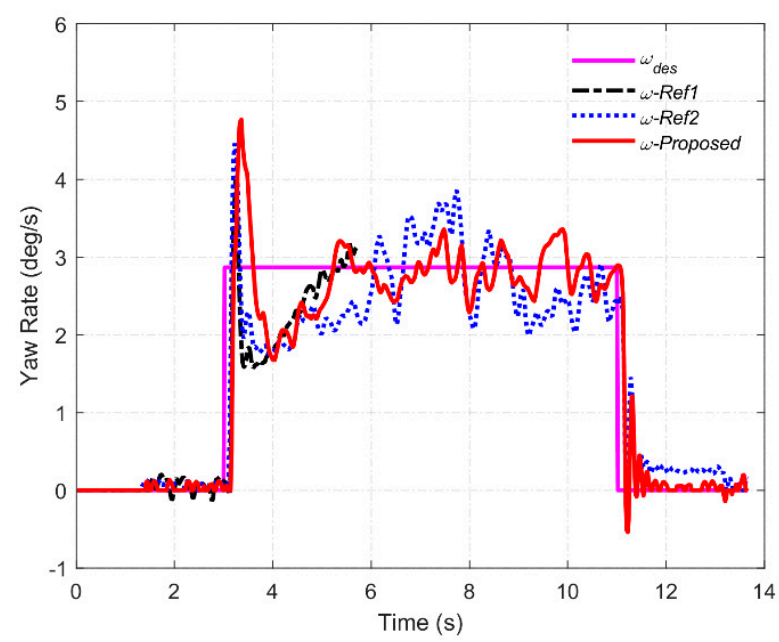

Figure 15. Yaw rate tracking.

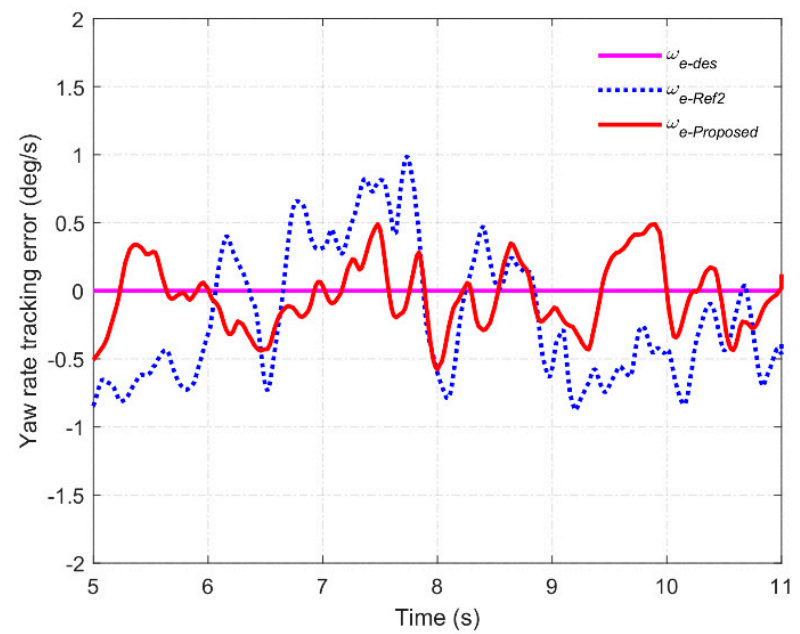

Figure 16. Yaw rate tracking error. 
Table 2. Tracking error analysis.

\begin{tabular}{cccc}
\hline Title 1 & MAE & RMSE & SD \\
\hline$v_{x e}$-Ref2 & 0.0433 & 0.0471 & 0.0294 \\
$v_{x e}$-Proposed & 0.0286 & 0.0341 & 0.0237 \\
$w_{e}$-Ref2 & 0.4688 & 0.0418 & 0.4922 \\
$w_{e}$-Proposed & 0.2133 & 0.0417 & 0.2509 \\
\hline
\end{tabular}

Figure 17 shows the desired torque of each motor with the three controllers. Figures 18 and 19 present the sideslip angles of the vehicle and the phase planes of the sideslip angle vs. yaw rate. It can be seen that the proposed controller has better stability performance than Ref2.

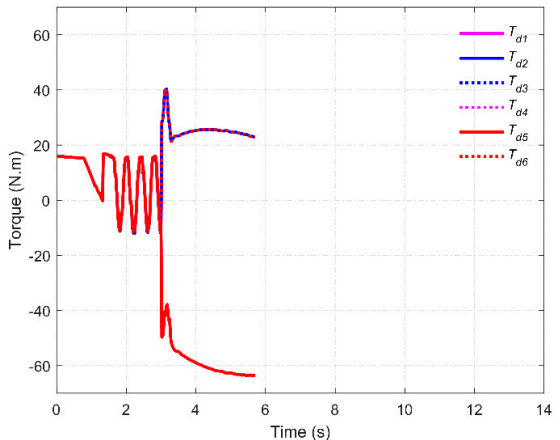

(a)

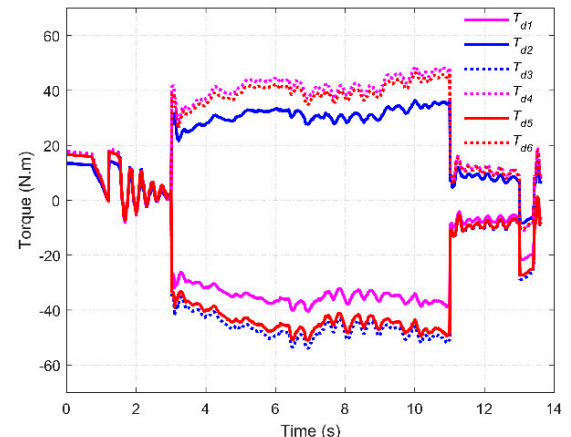

(b)

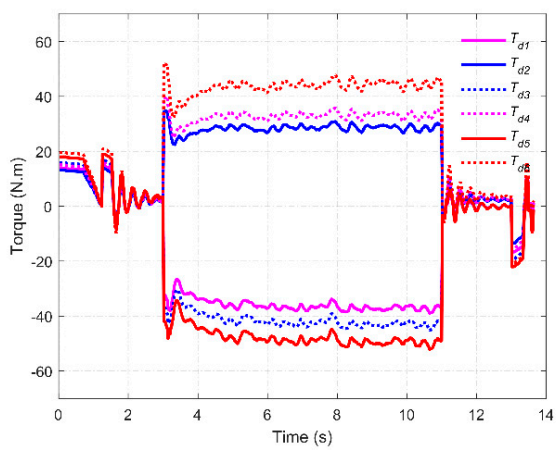

(c)

Figure 17. Torque on each wheel with three controllers: (a) Torque on each wheel with Ref1 controller; (b) Torque on each wheel with Ref2 controller; (c) Torque on each wheel with the proposed controller.

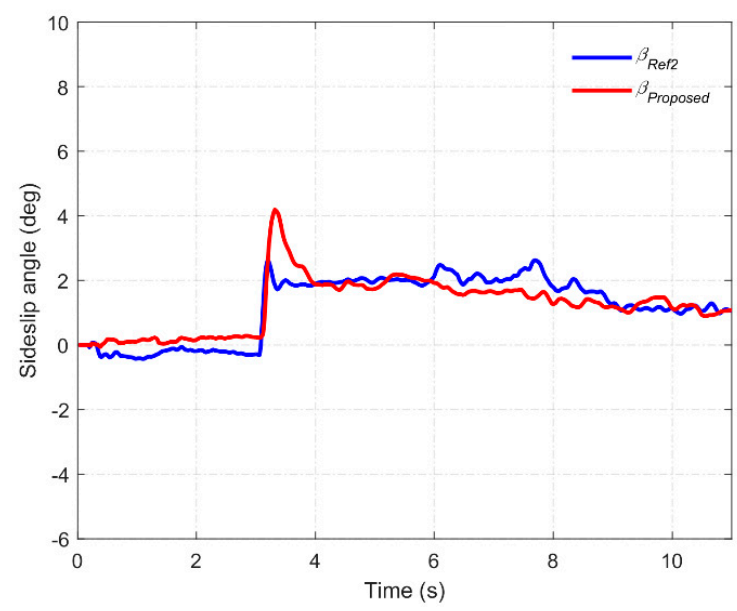

Figure 18. Comparison of sideslip angles. 


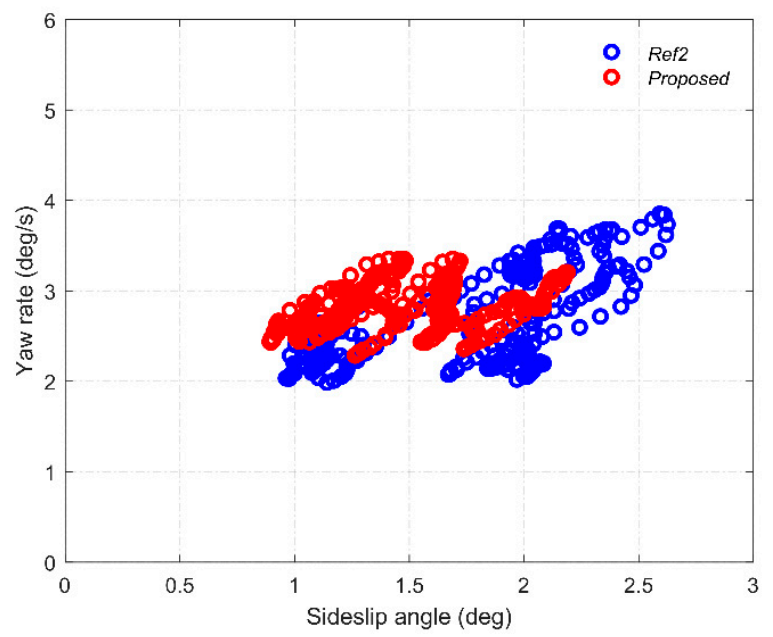

Figure 19. Comparison of phase planes.

\section{Conclusions}

In this paper, a driving force distribution and control strategy for a 6WD skid-steering EUGV actuated by independent drive wheels is proposed to improve the maneuverability and stability. The key conclusions include the following:

(1) The architecture of a 6WD skid-steering EUGV actuated by independent drive wheels was introduced. Focusing on longitudinal, lateral, and yaw motion, a nonlinear vehicle system dynamics model with nine DOFs was established. By using the Magic Formula tire model, the longitudinal and lateral tire forces in pure circumstances were introduced. In order to describe the actual forces of the tire, a dynamics model of the tire in the combined slip circumstances was developed.

(2) To improve the maneuverability and stability, a driving force distribution and control strategy was proposed. The control strategy was composed of hierarchical controllers, including an upper layer controller and lower layer controller. In the upper layer controller, the controlled resultant driving force and yaw moment were calculated to control the vehicle motion states to track the desired input by using the integral sliding mode control (ISMC) and proportion-integral-differential (PID) control method. In the lower layer controller, the controlled resultant driving force and yaw moment were realized by distributing the actuator motor's torque. An objective function consisting of the longitudinal tire workload rates and weight factors of the tire was established by considering the inequality constraints, including the actuator constraints, road adhesion constraints, and tire friction circle constraints. The weight factors were composed of the ratio of the tire vertical force considering the vehicle motion conditions and vertical load change of each tire. Based on the active set algorithm, the control distribution method was used to solve the objective function for optimal driving force allocation.

(3) Experimental tests were conducted to verify the effectiveness of the proposed control algorithm. Two types of testing scenarios were studied: motion in straight conditions and curved conditions. In addition, the rule-based driving force even allocation method and optimal driving force vectoring distribution method used in the related references were experimented with for comparison. The experimental results demonstrate that the proposed control strategy had excellent performance in vehicle maneuverability and stability. In the curve-tracking condition, compared to Ref2, the longitudinal velocity tracking error and yaw rate tracking error were decreased by $33.9 \%$ and $54.5 \%$ with the proposed controller in the tracking stabilization stage, respectively. In the future, we will test the experimental platform in different scenarios with different terrains or banks or other more complex situations to test and investigate the robustness of our proposed control method.

Author Contributions: Conceptualization, H.Z. and H.L.; investigation, H.Z.; methodology, H.Z.; software, H.Z. and X.T.; validation, H.Z., H.L., and X.T.; data curation, H.Z. and R.B.; writing- 
original draft preparation, H.Z.; writing-review and editing, H.L. and B.Y.; supervision, H.L. and B.Y.; project administration, Y.D.; funding acquisition, H.L. All authors have read and agreed to the published version of the manuscript.

Funding: This work was supported by the National Key Research and Development Program of China (Nos. 2016YFD0701401, 2017YFD0700303 and 2018YFD0700602); Youth Innovation Promotion Association of the Chinese Academy of Sciences (Grant No. 2017488); Key Supported Project in the Thirteenth Five-year Plan of the Hefei Institutes of Physical Science, Chinese Academy of Sciences (Grant No.KP-2017-35, KP-2017-13 and KP-2019-16); Independent Research Project of the Research Institute of Robotics and Intelligent Manufacturing Innovation, Chinese Academy of Sciences (Grant No. C2018005); and Technological Innovation Project for New Energy and Intelligent Networked Automobile Industry of Anhui Province.

Data Availability Statement: The data used to support the findings of this study are available from the corresponding author upon request.

Conflicts of Interest: The authors declare that there is no conflict of interest.

\section{Abbreviations}

a Distance from center of gravity to the middle axle

$\beta \quad$ Vehicle sideslip angle

$a_{x} \quad$ Longitudinal acceleration

$a_{x d e s} \quad$ Desired longitudinal acceleration

$a_{y} \quad$ Lateral acceleration

$B \quad$ Vehicle width

$H \quad$ Height of center of gravity

$F_{x i} \quad$ Longitudinal force of the $i$ th tire $(i=1,2, \cdots, 6)$

$F_{x i d} \quad$ Desired longitudinal force of the $i$ th tire $(i=1,2, \cdots, 6)$

$F_{y i} \quad$ Lateral force of the $i$ th tire $(i=1,2, \cdots, 6)$

$F_{z i} \quad$ Vertical force of the $i$ th tire $(i=1,2, \cdots, 6)$

$F_{x} \quad$ Total longitudinal force at the center of gravity

$F_{y} \quad$ Total lateral force at the center of gravity

g Acceleration of gravity

$I_{z} \quad$ Yaw moment of inertia of the vehicle

$J_{w} \quad$ Rotation moment of the wheel

$l_{1} \quad$ Distance from front axle to middle axle

$l_{2} \quad$ Distance from middle axle to rear axle

$m \quad$ Vehicle total mass

$M_{F x} \quad$ Resultant moment produced by longitudinal force of tire

$M_{F y} \quad$ Resultant moment produced by lateral force of tire

$R \quad$ Wheel effective radius

$T_{i} \quad$ Torque of the $i$ th wheel $(i=1,2, \cdots, 6)$

$T_{d i} \quad$ Desired torque of the $i$ th wheel $(i=1,2, \cdots, 6)$

$v_{x} \quad$ Vehicle longitudinal velocity

$v_{x d e s} \quad$ Desired vehicle longitudinal velocity

$v_{y} \quad$ Vehicle lateral velocity

$\omega \quad$ Vehicle yaw rate

$\omega_{\text {des }}$ Desired vehicle yaw rate

$v_{x i} \quad$ Longitudinal velocity of the $i$ th wheel $(i=1,2, \cdots, 6)$

$v_{y i} \quad$ Lateral velocity of the $i$ th wheel $(i=1,2, \cdots, 6)$

$\omega_{w i} \quad$ Rotation velocity of the $i$ th wheel $(i=1,2, \cdots, 6)$

$\alpha_{i} \quad$ Sideslip angle of the $i$ th tire $(i=1,2, \cdots, 6)$

$\lambda_{i} \quad$ Slip rate of the $i$ th tire $(i=1,2, \cdots, 6)$

$\eta_{i} \quad$ Longitudinal force workload rate of the $i$ th tire $(i=1,2, \cdots, 6)$

$\mu_{i} \quad$ Coefficient of friction between road and the $i$ th tire $(i=1,2, \cdots, 6)$ 


\section{References}

1. Ahmed, M.; El-Gindy, M.; Lang, H.; Omar, M. Development of Active Rear Axles Steering Controller for 8X8 Combat Vehicle; SAE Technical Paper; SAE International: Warrendale, PA, USA, 2020.

2. Shuai, Z.; Li, C.; Gai, J.; Han, Z.; Zeng, G.; Zhou, G. Coordinated motion and powertrain control of a series-parallel hybrid $8 \times 8$ vehicle with electric wheels. Mech. Syst. Sig. Process. 2019, 120, 560-583. [CrossRef]

3. D'Urso, P.; El-Gindy, M. Development of control strategies of a multi-wheeled combat vehicle. Int. J. Autom. Control 2018, 12, 325-360. [CrossRef]

4. Lam, A.Y.S.; Leung, Y.-W.; Chu, X. Autonomous-Vehicle Public Transportation System: Scheduling and Admission Control. IEEE Trans. Intell. Transp. Syst. 2016, 17, 1210-1226. [CrossRef]

5. Kayacan, E.; Ramon, H.; Saeys, W. Robust Trajectory Tracking Error Model-Based Predictive Control for Unmanned Ground Vehicles. IEEE-ASME Trans. Mechatron. 2016, 21, 806-814. [CrossRef]

6. Huang, W.; Wen, D.; Geng, J.; Zheng, N.-N. Task-Specific Performance Evaluation of UGVs: Case Studies at the IVFC. IEEE Trans. Intell. Transp. Syst. 2014, 15, 1969-1979. [CrossRef]

7. Wu, X.; Hu, X.; Moura, S.; Yin, X.; Pickert, V. Stochastic control of smart home energy management with plug-in electric vehicle battery energy storage and photovoltaic array. J. Power Sources 2016, 333, 203-212. [CrossRef]

8. Boulon, L.; Hissel, D.; Bouscayrol, A.; Pape, O.; Pera, M.-C. Simulation Model of a Military HEV with a Highly Redundant Architecture. IEEE Trans. Veh. Technol. 2010, 59, 2654-2663. [CrossRef]

9. Li, Z.; Zheng, L.; Gao, W.; Zhan, Z. Electromechanical Coupling Mechanism and Control Strategy for In-Wheel-Motor-Driven Electric Vehicles. IEEE Trans. Ind. Electron. 2019, 66, 4524-4533. [CrossRef]

10. De Carvalho Pinheiro, H.; Ferraris, A.; Galanzino, E.; Sisca, L.; Carello, M.; Airale, A.; Messana, A. All-Wheel Drive Electric Vehicle Modeling and Performance Optimization; SAE Technical Paper 2019-36-0197; SAE International: Warrendale, PA, USA, 2020. [CrossRef]

11. Asiabar, A.N.; Kazemi, R. A direct yaw moment controller for a four in-wheel motor drive electric vehicle using adaptive sliding mode control. Proc. Inst. Mech. Eng. Part K J. Multi-Body Dyn. 2019, 233, 549-567. [CrossRef]

12. Carvalho Pinheiro, H.; Messana, A.; Sisca, L.; Ferraris, A.; Airale, A.G.; Carello, M. Torque Vectoring in Electric Vehicles with In-wheel Motors. In Advances in Mechanism and Machine Science; Springer: Cham, Germany, 2019; Volume 73, pp. 3127-3136. [CrossRef]

13. Huang, X.Y.; Zhang, H.; Zhang, G.G.; Wang, J.M. Robust Weighted Gain-Scheduling H-infinity Vehicle Lateral Motion Control With Considerations of Steering System Backlash-Type Hysteresis. IEEE Trans. Control Syst. Technol. 2014, 22, 1740-1753. [CrossRef]

14. Zhao, H.Y.; Chen, W.X.; Zhao, J.Y.; Zhang, Y.L.; Chen, H. Modular Integrated Longitudinal, Lateral, and Vertical Vehicle Stability Control for Distributed Electric Vehicles. IEEE Trans. Veh. Technol. 2019, 68, 1327-1338. [CrossRef]

15. Song, Y.T.; Shu, H.Y.; Chen, X.B.; Luo, S. Direct-yaw-moment control of four-wheel-drive electrical vehicle based on lateral tyre-road forces and sideslip angle observer. IET Intel. Transp. Syst. 2019, 13, 303-312. [CrossRef]

16. Kang, J.; Yoo, J.; Yi, K. Driving Control Algorithm for Maneuverability, Lateral Stability, and Rollover Prevention of 4WD Electric Vehicles with Independently Driven Front and Rear Wheels. IEEE Trans. Veh. Technol. 2011, 60, 2987-3001. [CrossRef]

17. Xiong, L.; Yu, Z.; Wang, Y.; Yang, C.; Meng, Y. Vehicle dynamics control of four in-wheel motor drive electric vehicle using gain scheduling based on tyre cornering stiffness estimation. Veh. Syst. Dyn. 2012, 50, 831-846. [CrossRef]

18. Zhou, H.L.; Jia, F.J.; Jing, H.H.; Liu, Z.Y.; Guvenc, L. Coordinated Longitudinal and Lateral Motion Control for Four Wheel Independent Motor-Drive Electric Vehicle. IEEE Trans. Veh. Technol. 2018, 67, 3782-3790. [CrossRef]

19. Nahidi, A.; Kasaiezadeh, A.; Khosravani, S.; Khajepour, A.; Chen, S.-K.; Litkouhi, B. Modular integrated longitudinal and lateral vehicle stability control for electric vehicles. Mechatronics 2017, 44, 60-70. [CrossRef]

20. Zhai, L.; Sun, T.M.; Wang, J. Electronic Stability Control Based on Motor Driving and Braking Torque Distribution for a Four In-Wheel Motor Drive Electric Vehicle. IEEE Trans. Veh. Technol. 2016, 65, 4726-4739. [CrossRef]

21. Wang, Y.F.; Fujimoto, H.; Hara, S. Torque Distribution-Based Range Extension Control System for Longitudinal Motion of Electric Vehicles by LTI Modeling with Generalized Frequency Variable. IEEE-ASME Trans. Mechatron. 2016, 21, 443-452. [CrossRef]

22. Yuan, X.B.; Wang, J.B. Torque Distribution Strategy for a Front- and Rear-Wheel-Driven Electric Vehicle. IEEE Trans. Veh. Technol. 2012, 61, 3365-3374. [CrossRef]

23. Liu, M.; Huang, J.; Cao, M. Handling Stability Improvement for a Four-Axle Hybrid Electric Ground Vehicle Driven by In-Wheel Motors. IEEE Access 2018, 6, 2668-2682. [CrossRef]

24. Boyd, S.; Boyd, S.P.; Vandenberghe, L. Convex Optimization; Cambridge University Press: Cambridge, UK, 2004.

25. De Novellis, L.; Sorniotti, A.; Gruber, P. Wheel Torque Distribution Criteria for Electric Vehicles with Torque-Vectoring Differentials. IEEE Trans. Veh. Technol. 2014, 63, 1593-1602. [CrossRef]

26. Zhao, H.Y.; Gao, B.Z.; Ren, B.T.; Chen, H.; Deng, W.W. Model predictive control allocation for stability improvement of four-wheel drive electric vehicles in critical driving condition. IET Control Theory Appl. 2015, 9, 2688-2696. [CrossRef]

27. Khosravani, S.; Jalali, M.; Khajepour, A.; Kasaiezadeh, A.; Chen, S.K.; Litkouhi, B. Application of Lexicographic Optimization Method to Integrated Vehicle Control Systems. IEEE Trans. Ind. Electron. 2018, 65, 9677-9686. [CrossRef]

28. Leng, B.; Xiong, L.; Yu, Z.P.; Zou, T. Allocation control algorithms design and comparison based on distributed drive electric vehicles. Int. J. Automot. Technol. 2018, 19, 55-62. [CrossRef] 
29. Xiong, L.; Teng, G.W.; Yu, Z.P.; Zhang, W.X.; Feng, Y. Novel Stability Control Strategy for Distributed Drive Electric Vehicle Based on Driver Operation Intention. Int. J. Automot. Technol. 2016, 17, 651-663. [CrossRef]

30. Kim, W.; Yi, K.; Lee, J. An optimal traction, braking, and steering coordination strategy for stability and manoeuvrability of a six-wheel drive and six-wheel steer vehicle. Proc. Inst. Mech. Eng. Part D J. Automob. Eng. 2012, 226, 3-22. [CrossRef]

31. Kim, C.; Ashfaq, A.M.; Kim, S.; Back, S.; Kim, Y.; Hwang, S.; Jang, J.; Han, C. Motion Control of a 6WD/6WS Wheeled Platform with In-wheel Motors to Improve Its Maneuverability. Int. J. Control Autom. Syst. 2015, 13, 434-442. [CrossRef]

32. Zhao, Y.; Zhang, C.N. Electronic Stability Control for Improving Stability for an Eight In-Wheel Motor-Independent Drive Electric Vehicle. Shock Vib. 2019, 1-21. [CrossRef]

33. Kim, W.; Yi, K.; Lee, J. Drive control algorithm for an independent 8 in-wheel motor drive vehicle. J. Mech. Sci. Technol. 2011, 25, 1573-1581. [CrossRef]

34. Pacejka, H. Tire and Vehicle Dynamics; Elsevier: Amsterdam, The Netherlands, 2005.

35. Cordeiro, R.A.; Victorino, A.C.; Azinheira, J.R.; Ferreira, P.A.V.; de Paiva, E.C.; Bueno, S.S. Estimation of Vertical, Lateral, and Longitudinal Tire Forces in Four-Wheel Vehicles Using a Delayed Interconnected Cascade-Observer Structure. IEEE/ASME Trans. Mechatron. 2019, 24, 561-571. [CrossRef] 